\title{
Evaluation of climatic and geographical effects on bioactive compounds and minerals profile of two selected samples of white turnip
}

\author{
Tahir Mehmood ${ }^{1 *}$, Shehla Bashir ${ }^{1}$, Faiza Siddique ${ }^{1}$, Mudassir Iqbal ${ }^{2}$, \\ Zahra Jabeen ${ }^{3}$ and Hina Arshad ${ }^{1}$ \\ 1. Department of Chemistry, University of Sargodha, 40100-Sargodha-Pakistan \\ 2. Department of Chemistry, School of Natural Sciences, National University of Sciences and Technology (NUST), \\ H-12, Islamabad, 44000-Pakistan \\ 3. Department of Applied Chemistry \& Biochemistry, Government College University, Faisalabad- Pakistan \\ *Corresponding author's email: tahiruosbiochem@yahoo.com
}

Citation

Tahir Mehmood, Shehla Bashir, FaizaSiddique, Mudassir Iqbal, Zahra Jabeen and Hina Arshad. Evaluation of climatic and geographical effects on bioactive compounds and minerals profile of two selected samples of white turnip. Pure and Applied Biology. Vol. 6, Issue 1, pp317-327. http://dx.doi.org/10.19045/bspab.2017.60030

Received: 05/01/2017

Revised: 20/02/2017

Accepted: 26/02/2017

Online First: 28/02/2017

\section{Abstract}

With the rise of various disorders in human beings related with free radicals perceived to recompense the scrutiny on synthetic and natural antioxidants to control the numerous perilous ailments and other carcinogenic hazardous diseases. Vegetables and fruits are the major source of natural antioxidants because these are majorly composed of natural antioxidants. Therefore, current study was carried out to focus on the significance and assessment of antioxidants in the ethanol and methanol extracts of turnip peels. Turnip samples were collected from two different regions of Pakistan i.e. Soon Valley and Sargodha region. Further two different solvent systems i.e. Methanol and Ethanol were used for each variety of turnip. Evaluated the antioxidant activity through DPPH (2, 2-diphenyl-1-picrylhydrazyl) radical scavenging activity, total flavonoid contents, determined the total phenolic contents via FolinCiocalteu method and reducing power assay. Estimation of mineral profile was done by wet digestion method. In the samples of turnip percentage yield of methanolic extracts exhibited maximum antioxidant activity as compared to ethanolic extracts. Analysis of results revealed that methanolic extract of Sargodha region turnip possessed maximum concentration of TPC (Total pheolic content) as compared to the $80 \%$ ethanolic extract of soon valley region. In $100 \%$ methanolic extract radical scavenging activity exhibited maximum \% inhibition as compared to ethanolic extract. In the extracts of turnip peels 100\% methanol exhibited greater reducing potential. Mineral composition and levels vary across two different samples of turnip indicated the maximum concentration of minerals in Sargodha region turnip. As a consequence of this study solvents that were used possessed significant results $(\mathrm{P}<0.05)$ for the antioxidant compounds extraction from turnip samples.

Keywords: Turnip; Antioxidant potential; Reducing powers; Moisture content; Minerals profile

\section{Introduction}

For human life fruits and vegetables are the vital permutation of nutrients because they contain different kind of vitamins, water, antioxidants, proteins, minerals, lipids, antioxidants, flavonoids and phenolics etc. 
Crucial diseases such as cardiovascular and cancer are generally restrained by daily utilization of fruits and vegetables. In our society increased rate of deaths occurs due to these diseases. Possibility of various diseases like Alzheimer disease, cancer and other ailments that are linked with human health can be declined by the intake of vegetables and fruits [1]. Phenolic antioxidants terminate free radicals and often act as metal chelators [2].

Compounds that inhibit the effect of free radicals generated by various metabolic mechanisms of body are called antioxidants. With the passage of time and progression of technologies, studies disclosed the significance of antioxidants [3]. Fruits and vegetables made up of substantial amount of dietary antioxidants which prevent the cells from aging and encourage the new cells growth.

Qualitative food is a vital demand of all human beings that dispense them different nutrients like vitamins, carbohydrates, minerals and protein in their daily uptake. For the scarcity of these nutrients fruits and vegetables appraised as extensive way. Scarcity of nutrients becomes the reason of numerous ailments as linked with human health [4]. In our body liquids and tissues inorganic components like minerals are responsible for the suitable working of many functions of biological system. Chemically minerals are employed by various sources in human body and considered as essential elements [5]. From different sources intake of minerals manifested the nutritional advantage in various physiological functions and lack of minerals causes significant health issues. Minerals insufficiency is very menacing to human health.

Vitamin C protects us from cancer, diabetes, high blood pressure and obesity by arresting the process of oxidation and enormously found in turnip which is a brassica vegetable. Cruciferous root vegetable
Brassica rapa is circular in shape with purple crown and in white colour, holding green leaves at top. Annually Brassica rapa is grown-up in European countries but normally it is found in winter season of year from October to March. Vitamin C and antioxidants contributed by turnip terminate the oxidation processes that produce oxidative stress. Valuable substances are present in Brassica rapa that lessen the possibility of numerous diseases [6].

Functional constituents in natural sources are affected by varieties, cultivation, Climatic and Geographical influences. Thus, the nature of extracting solvents plays an important role in the yield of extracts, their antioxidant activities and other important properties. In this scenario, we were motivated to evaluate bioactive attributes, biological activities, minerals profile and other antioxidant compounds found in white turnip extracted by different solvents system, to optimize the extraction process and to check the geographical effects on cultivars.

\section{Materials and methods}

\section{Sample preparation and extraction}

Earlier than extraction, selected varieties of turnip from two different areas i.e. Sargodha and Soon valley were physically cleansed and swabbed with deionized distilled water. Separate out the peels from pulp of turnip samples and cut them into small segments, after that dehydrated the samples of turnip at room temperature in shadow. To resolve the content of moisture in an electric oven these samples were placed for 2 hours at $100^{\circ} \mathrm{C}$ before exposure to air. After the step of drying, samples of turnip were minced into powder of fine particles then moved all the powder of fine particles across the $1 \mathrm{~mm}$ strainer. The moisture of fresh samples was calculated by using formula. All chemicals that were employed in different experiments of this study were analytical grade and 
purchased from Sigma-Aldrich Chemical Corporation, Germany.

\section{Sample extraction}

In the extraction procedure all the fine powder material was specifically $10 \mathrm{~g}$ measured and accomplished the extraction in $100 \mathrm{~mL}(1: 10)$ of two distinct solvents i.e. methanol and ethanol. The extraction was done through (OS- 752) shaker at $170 \mathrm{rpm}$ for 6 hours [7]. The extraction was repeated thrice in order to complete extraction of phenolic compounds and minerals. After that these extracts were filtered and for the evaporation of solvents passed these samples below the reduced pressure of $45^{\circ} \mathrm{C}$ through rotary evaporator. After the solvents evaporation remnants are obtained and labelled the obtained residues for the perseverance of yield \%.

\section{Determination of antioxidant activity Determination of TPC (Total phenolic content)}

Assess the total contents of phenolic substances in dissimilar samples of Brassica rapa via Folin-Ciocalteu using spectrophotometer. Mixture of reaction was made by mixing $+0.5 \mathrm{~N}$ Folin reagent + $1 \mathrm{~mL}$ sample extract $(0.1 \mathrm{~mL})$ of turnip. Then leave it at room temperature for 15 minutes. After that added $2.5 \mathrm{ml}$ of $7 \%$ saturated $\mathrm{Na}_{2} \mathrm{CO}_{3}$ and left it in dark for 30 minutes. Through spectrophotometer absorbance at $760 \mathrm{~nm}$ was noted with a $1 \mathrm{~cm}$ cell. Manipulated the Gallic acid as calibration standard and calculating the results in mg/100g. The assay was performed three times and average results were obtained [8].

\section{Determination of TFC (Total flavonoid content)}

$50 \mathrm{mg}$ of Brassica rapa samples extracts were added in $1 \mathrm{~mL}$ of distilled water then added $4 \mathrm{~mL}$ of distilled water in order to make the volume up to $5 \mathrm{~mL}$. Further added $0.3 \mathrm{~mL}$ of $5 \% \mathrm{NaNO}_{3}$ and left this mixture for 5 minutes. Add $3 \mathrm{~mL}$ of $10 \% \mathrm{AlCl}_{3}$ to the reaction mixture. Then add $2 \mathrm{ml} \mathrm{NaOH} 1 \mathrm{M}$ after 6 minutes. Through UV spectrophotometer absorbance was measured at $510 \mathrm{~nm}$ [9]. Values of TFC were showed in $\mathrm{mg} / 100 \mathrm{~g}$. Catechin was manipulated as a calibration standard. The analysis was performed three times and average results were obtained.

\section{DPPH scavenging activity assay}

Evaluation of DPPH examination was executed for the analysis of free radicals in the sample solution. Analysis of antioxidant activity of turnip samples from two different areas was also determined by conducting the DPPH scavenging assessment through spectrophotometer. For this reason, reaction mixture was prepared by dissolving $10 \mathrm{mg}$ of sample in $1 \mathrm{~mL}$ distilled water. Six varied concentration of standard $(0.25,0.5,0.75$, 1, 1.5 and 2) $\mathrm{mg} / \mathrm{mL}$ were prepared. After that added distilled water in order to make the volume up to $400 \mu \mathrm{L}$. In each test tube added $2 \mathrm{~mL}$ of DPPH reagent $(0.1 \mathrm{mM})$. $0.1 \mathrm{mM}$ DPPH reagent solution was made by dissolving $10 \mathrm{mg}$ DPPH in $50 \mathrm{ml}$ of methanol. After adding DPPH reagent solution all the sample solutions were left for 30 minutes in dark. By using a standard Butyl hydroxyl anisole (BHA) absorbance was measured at $517 \mathrm{~nm}$ [10].

$\%$ Inhibition $=$ Absorbance $($ Blank $)$-Absorbance $($ sample $) \times 100$ Absorbance (Blank)

\section{Reducing power assay}

Reducing power ability of the Brassica rapa samples from two different areas was determined by reducing power assay. In this method $50 \mathrm{mg}$ of samples extracts of turnip were dissolved in to $5 \mathrm{~mL}$ of Sodium phosphate buffer $\mathrm{NaH}_{2} \mathrm{PO}_{4}$ acid $=29.94 \mathrm{~g}$, $\mathrm{NaHPO}_{4} \quad$ base=7.146g, $\mathrm{pH}=6.6$ ). Then potassium ferricyanide $(1.0 \%, 2 \mathrm{~mL})$ was added into reaction mixture and kept this reaction mixture at $50^{\circ} \mathrm{C}$ for 20 minutes. Added $2 \mathrm{~mL}$ of $10 \%$ trichloroacetic acid and kept it in a centrifuge for 10 minutes $(220 \mathrm{v}-$ CHINA) at $980 \mathrm{rpm}$. After the centrifugation of reaction mixture upper 
most film of solution $(2.5 \mathrm{~mL})$ was diluted with $2.5 \mathrm{~mL}$ distilled water and ferric chloride $(0.5 \mathrm{~mL}, 0.1 \%)$ was added in to the reaction mixture. The absorbance at $700 \mathrm{~nm}$ was recorded by using spectrophotometer. The experiment was performed three times and average results were obtained [11].

\section{Estimation of mineral profile}

For the analysis of minerals in the samples of Brassica rapa from two different areas, the labelled samples were used for evaluation of minerals as SV (Soon valley turnip), SS (Sargodha turnip).

\section{Wet digestion method}

In this method of wet digestion, measured $2 \mathrm{~g}$ each of the dried samples of Brassica rapa and put them in to four isolated beakers. One beaker was labelled as blank. Then $20 \mathrm{~mL}$ of nitric acid was added in to the samples of turnip and kept at the temperature of $70-90^{\circ} \mathrm{C}$ on an electric hot plate for 2 hours in a fume hood chamber. After 10 minutes burning of sample with nitric acid, 3-5mL $\mathrm{H}_{2} \mathrm{O}_{2}(30 \%)$ was added and gently added nitric acid in to each beaker. In an empty beaker nitric acid was also added and labelled as blank. The hot plate temperature was elevated up to 120 $130^{\circ} \mathrm{C}$ after 2 hours and settled the sample with constant addition of hydrogen peroxide and nitric acid for 1 hour. All solutions amount was conserved from 25 to $30 \mathrm{~mL}$. Process of digestion was continued till the solutions turned in to transparent. Then solutions were sanctioned to cool and percolated the cool solutions with filter paper of Whatmann $(0.4 \mu \mathrm{m})$. After the filtration process distilled water was added to make the final volume up to $30 \mathrm{~mL}$ [12].

\section{Mineral analysis}

Assessment of mineral profile from the turnip samples was carried out by making different standard solutions of $\mathrm{Ni}^{2+}, \mathrm{Cr}^{3+}$, $\mathrm{Co}^{3+}, \mathrm{Cu}^{2+}$ and $\mathrm{Cd}^{2+}$. Prepare all these standards by the stock solution of $1000 \mathrm{mg} /$ L. For the analysis of each element six concentrations of standard were prepared (5ppm, 10ppm, 15ppm, 20ppm, 25ppm and 30ppm).

Standards were prepared by using formula

$$
\mathrm{C}_{1} \mathrm{~V}_{1}=\mathrm{C}_{2} \mathrm{~V}_{2}
$$

Absorbance of different concentration of standards was determined by atomic absorption spectrophotometer (AAS). Plotted the absorbance versus concentration and the development of continuous curve resolved the accurate concentration of the sample. Since the calibration of varied concentration of elements reference reading was also taken. Results were assembled for statistical analysis [13].

\section{Statistical analysis}

All the preliminary efforts accomplished in the laboratory were replicated three times and statistical study of data was described as Mean \pm standard deviation [14].

\section{Results and discussion}

\section{Yield of crude extracts}

Brassica vegetables are considered as potential source of antioxidants, intensely nutritional value and have substantial proposed health effects on human beings. Materials obtained from plant species can be extracted in particular solvents and greatly depend upon nature, concentration of the solvent utilization, and their mixing up performance [15]. For the ultimate extraction of antioxidant compounds appropriate approaches are required. In dissimilar solvents ethanol $(80 \%, 100 \%)$ and methanol $(80 \%, 100 \%) \%$ yield of turnip samples from two regions Sargodha and Soon valley was determined. In the samples of Brassica rapa \% yield of methanolic extracts possessed higher antioxidant activity as correlated with ethanolic extracts.

\section{Moisture content}

Current investigation was conducted to estimate the biochemical configuration of two varieties of Brassica rapa peels to determine the content of moisture between Sargodha and Soon valley samples. 
Proximate investigation of two dissimilar turnip samples content of moisture was analysed as shown in Figure 1. Different moisture content values were recognized in each gram of sample with the help of analysis of variance. Statistical study revealed significant variations $(\mathrm{P}>0.05)$ among 5g sample from both regions [16, 17]. The error bar on the data indicates the error value.

Content of moisture in Sargodha region sample of turnip revealed maximum $\%$ in contrast to Soon valley region sample.

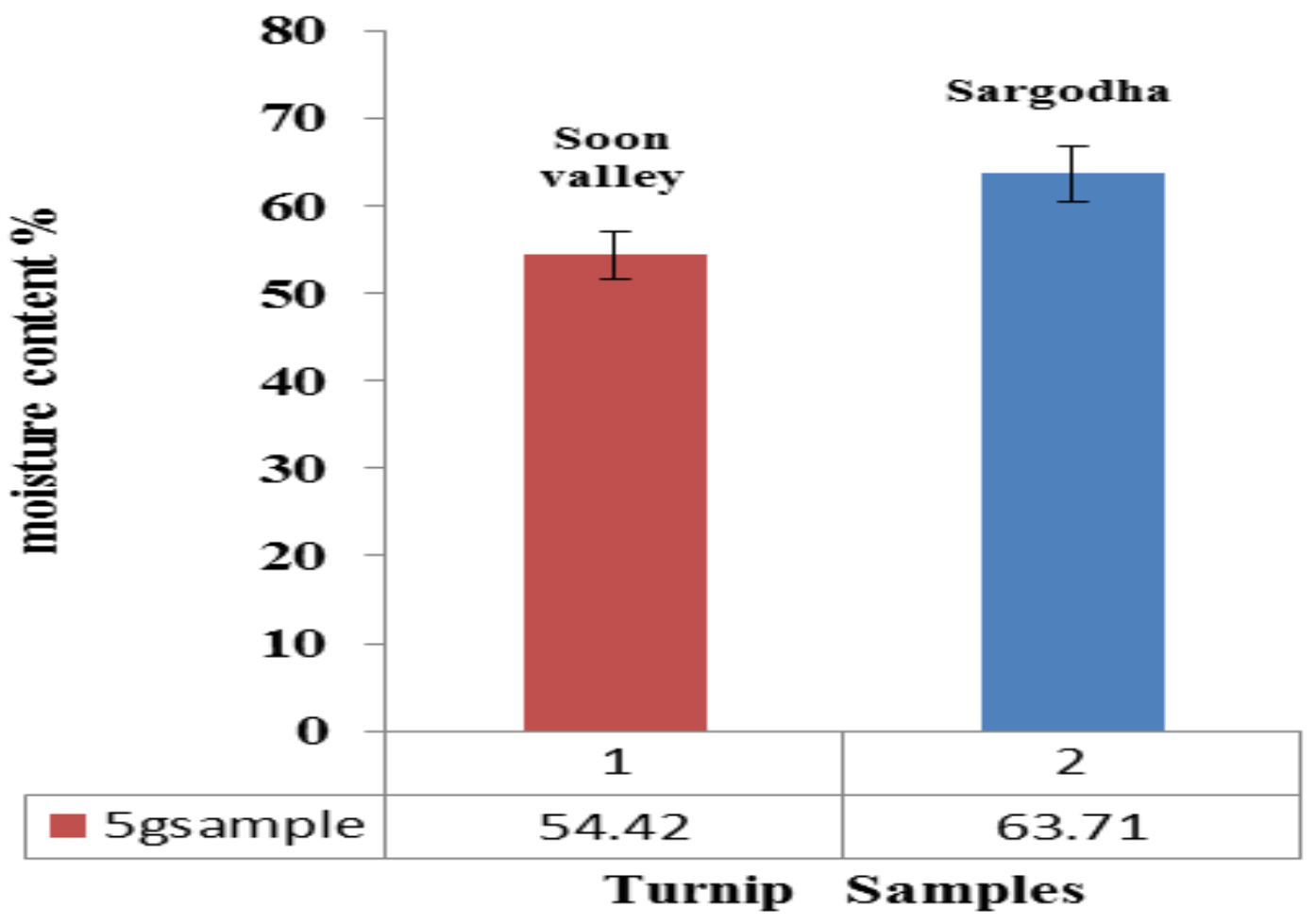

\section{Figure 1. Moisture content}

\section{Total phenolic contents}

Secondary metabolites that are derived by plant products such as fruits and vegetables are known as phenolic contents [18]. Total phenolic contents of Sargodha and Soon valley samples of turnip were illustrated. Analysis showed difference in $80 \%$ and $100 \%$ (methanolic, ethanolic) solvents extracts that were assessed by employing Folin-Ciocalteu method and using Gallic acid as standard for its amplified potency, lesser intervention as well as expeditious analysis of phenolics [19]. Analysis of soon valley and Sargodha region turnip peels possessed higher quantity of total phenolic contents in $100 \%$ methanolic extracts as correlated with $80 \%$ ethanolic extracts as shown in Figure 2. Analysis of variance revealed significant effects $(\mathrm{P}<0.0 .5)$. These both solvents demonstrated to be very efficacious in TPC. 


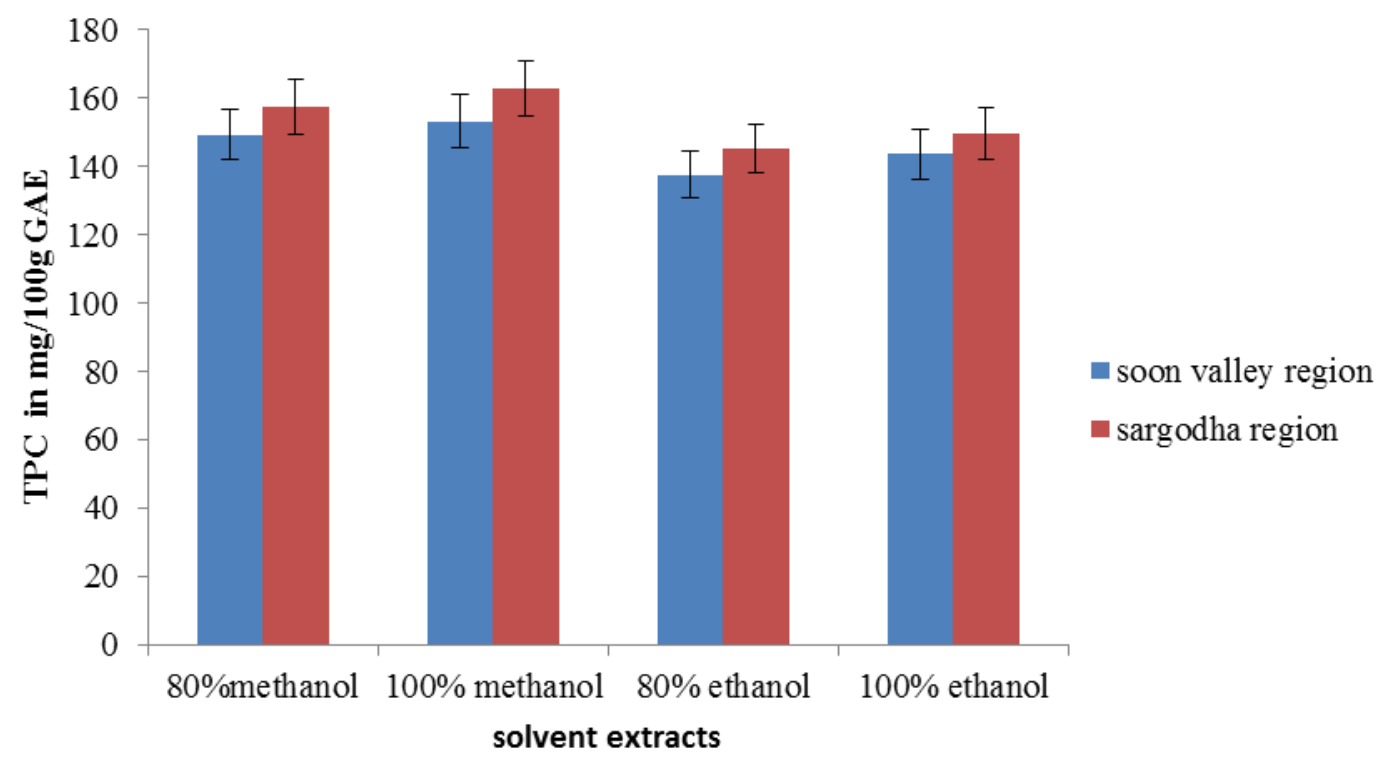

Figure 2. Total phenolic content of turnip sample

\section{Total flavonoid content}

Plants appraised as affluent source of flavonoids contributing the potent antioxidant activity, granted as the most significant phenolics in plants preventing the oxidation of lipoproteins [20]. Total flavonoid contents $(\mathrm{mg} / 100 \mathrm{~g})$ of turnip peel samples from Sargodha and Soon valley in both ethanol $(80 \%, 100 \%)$ and methanol
(80\%, 100\%) solvents were determined as shown in Figure 3. $100 \%$ methanolic extracts of both regions revealed highest amount of TFC. Methanolic extract of Sargodha region possessed highest TFC values. Analysis of variance showed significant results $(\mathrm{p}<0.05)$ in different extracts [21].

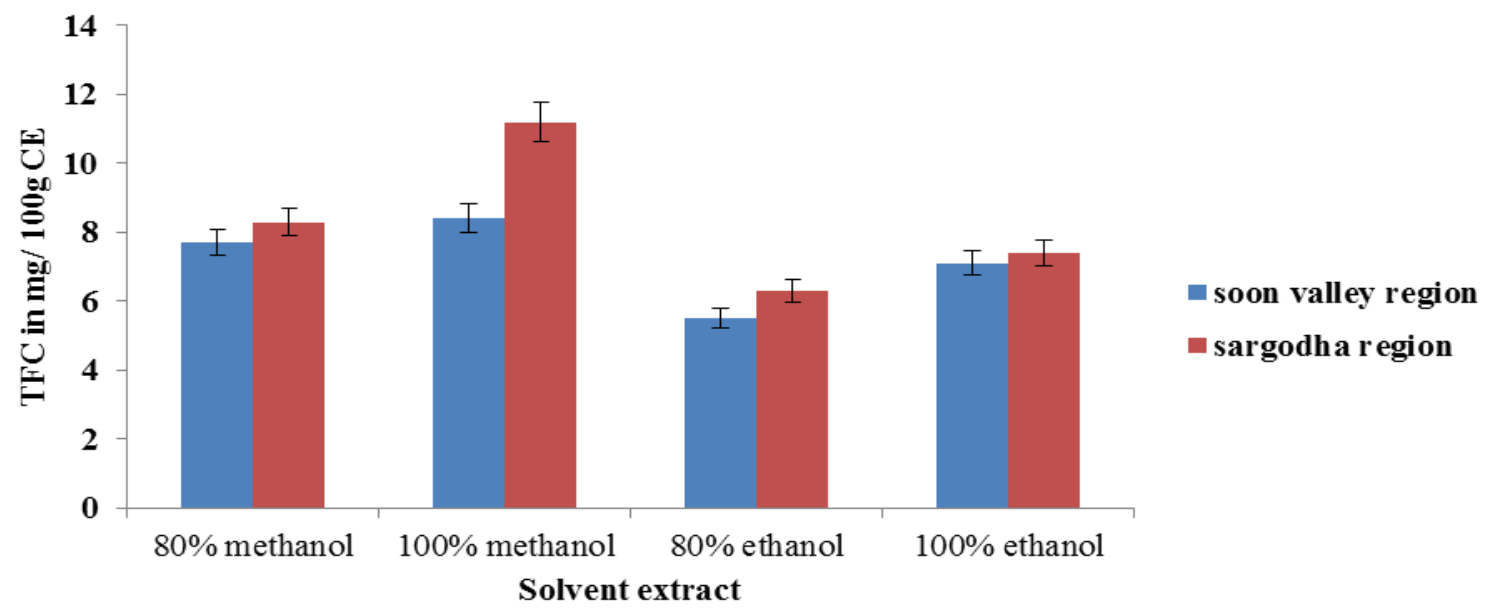

Figure 3. Total flavonoid content of turnip sample

Percentage inhibition of radical DPPH

Radical scavenging activity grants a fundamental function for human beings because free radicals are very dangerous to our health because they are elaborated in various diseases such as cataracts, aging, cancer, brain dysfunction besides cardiovascular disorders. In alcoholic 
solution, by stabilizing free radical, DPPH provides as a perfect substrate. To determine the antioxidant prospective of various fruits and vegetables free radical was employed [22]. DPPH is known for stabilizing free radical because it attains hydrogen and electron, thus stabilizing the free radicals that are responsible for many ailments in human body.

Radical scavenging activity is assessed by its reducing absorbance as long as DPPH

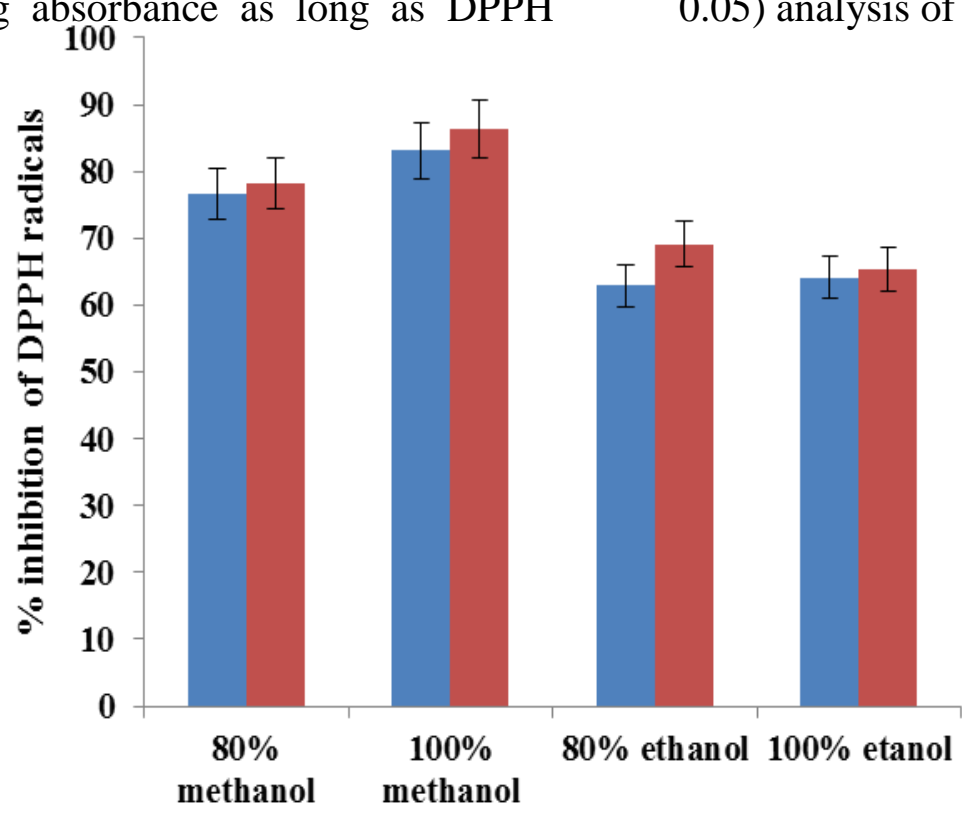

Sovent extracts reaction that is executed at 517nm [6]. Both samples of Brassica rapa peels revealed considerable amount of radical scavenging activity as shown in Figure 4. This scavenging activity showed variation with the previous scrutinized activity. In the prevailing investigation the activity of 100 $\%$ methanol from the samples of Brassica rapa exhibited maximum \% inhibition of radical DPPH and showed significant $(\mathrm{P}<$ $0.05)$ analysis of variance. w soon valley region

sargodha region

Figure 4. DPPH radical scavenging activity of turnip sample

\section{FRAP assay}

FRAP (ferric reducing antioxidant power assay) is a kind of added component for the determination of antioxidant activity swiftly, reproducibly, as well as quietly. Allocated comparable results of authenticity with distilled water and dissimilar solvents. In this practice according to the principle with the change of colour iron is reduced to another form. Reducing activity of the substances confined on the certainty of colour stability, maximal colour acknowledged as greater antioxidant activity [23].
Table 1 illustrated the reducing potential of varied extracts of Brassica rapa in dissimilar solvents. Concentration was deliberated in $\mathrm{mg} / \mathrm{mL}$, with the rise in concentration of the samples of turnip, reducing activity was lifted. Correlation of Brassica rapa samples from both regions Sargodha and Soon valley showed that $100 \%$ methanol possessed highest antioxidant activity as related to other sample extracts. Statistical study interpreted significant $(\mathrm{P}<0.05)$ discrepancy between two assortments of Soon valley and Sargodha region. 
Table 1. Effect of reducing power assay on turnips from two different origins

\begin{tabular}{|l|c|c|c|}
\hline Solvents & Conc.(mg/mL) & Soon valley (S.V) & Sargodha (S.S) \\
\hline $\mathbf{8 0 \% M e t h a n o l ~}$ & 0.25 & $1.94 \pm 0.06$ & $1.98 \pm 0.05$ \\
\hline & 0.5 & $2.05 \pm 0.08$ & $2.27 \pm 0.06$ \\
\hline & 0.75 & $2.43 \pm 0.04$ & $2.69 \pm 0.07$ \\
\hline & 1.0 & $2.87 \pm 0.04$ & $2.96 \pm 0.08$ \\
\hline $\mathbf{1 0 0 \%}$ Methanol & 1.5 & $3.21 \pm 0.05$ & $3.45 \pm 0.09$ \\
\hline & 0.25 & $1.98 \pm 0.01$ & $2.12 \pm 0.04$ \\
\hline & 0.5 & $2.18 \pm 0.03$ & $2.38 \pm 0.04$ \\
\hline & 0.75 & $2.53 \pm 0.05$ & $2.76 \pm 0.07$ \\
\hline & 1.0 & $2.83 \pm 0.06$ & $3.55 \pm 0.08$ \\
\hline $\mathbf{8 0 \%}$ Ethanol & 1.5 & $3.64 \pm 0.03$ & $3.81 \pm 0.08$ \\
\hline & 0.25 & $1.82 \pm 0.02$ & $1.93 \pm 0.07$ \\
\hline & 0.5 & $1.98 \pm 0.05$ & $2.14 \pm 0.06$ \\
\hline & 0.75 & $2.16 \pm 0.04$ & $2.39 \pm 0.07$ \\
\hline & 1.0 & $2.48 \pm 0.06$ & $2.59 \pm 0.05$ \\
\hline $\mathbf{1 0 0 \%}$ ethanol & 1.5 & $2.61 \pm 0.05$ & $2.69 \pm 0.06$ \\
\hline & 0.25 & $1.91 \pm 0.04$ & $2.27 \pm 0.06$ \\
\hline & 0.5 & $2.44 \pm 0.02$ & $2.57 \pm 0.05$ \\
\hline & 0.75 & $2.59 \pm 0.06$ & $2.64 \pm 0.06$ \\
\hline & 1.0 & $2.71 \pm 0.06$ & $2.95 \pm 0.07$ \\
\hline & 1.5 & $3.13 \pm 0.08$ & $3.67 \pm 0.08$ \\
\hline
\end{tabular}

Values are mean $\pm S D(n=3)$ of three separate experiments

\section{Estimation of mineral profile and few heavy metals}

Minerals are contemplated inorganic substances that are generally requisite in lesser amounts on regular basis. Mineral contents intake in plants, human beings and animals significantly differ in various ratios. Calcium, phosphorous and iron concentrations differ in various purposes of body, for example $\mathrm{Ca}^{2+}$ is essential in the actual bone maintenance and also for the proper functioning of nerves as well as muscles [24]. Chief element of cytochrome, $\mathrm{Fe}^{3+}$, carries out cellular respiration. $\mathrm{Mg}^{2+}$ and $\mathrm{Zn}^{2+}$ serve as a cofactor in many enzymes and moreover in different biological paths.

Minerals are involved in fighting the diverse ailments that are extremely hazardous to health. Heavy metals in food cause dangerous health effects [25]. Estimation of minerals by wet ashing method is used to determine different types of minerals. Strong acids and oxidizing agents are used and heated in anticipation of the organic matter is digested. The main advantage of this method is less loss of mineral contents and it is more frequent than dry method because it takes less temperature. Current study analysed the heavy metal contents and mineral profile from wet ashing method in turnip samples from both regions Sargodha and Soon valley. Heavy metal determination from peels of Brassica rapa revealed that concentration of $\mathrm{Zn}^{2+}$ in turnip was highest i.e. $26.73 \mathrm{mg} / \mathrm{kg}$ in Soon valley and 34.21 $\mathrm{mg} / \mathrm{kg}$ in Sargodha region [26]. Study was executed to assess the antioxidant potential, content of moisture and minerals profile of samples of Brassica rapa from Sargodha and Soon valley. The result of minerals is shown in Figure 5. 


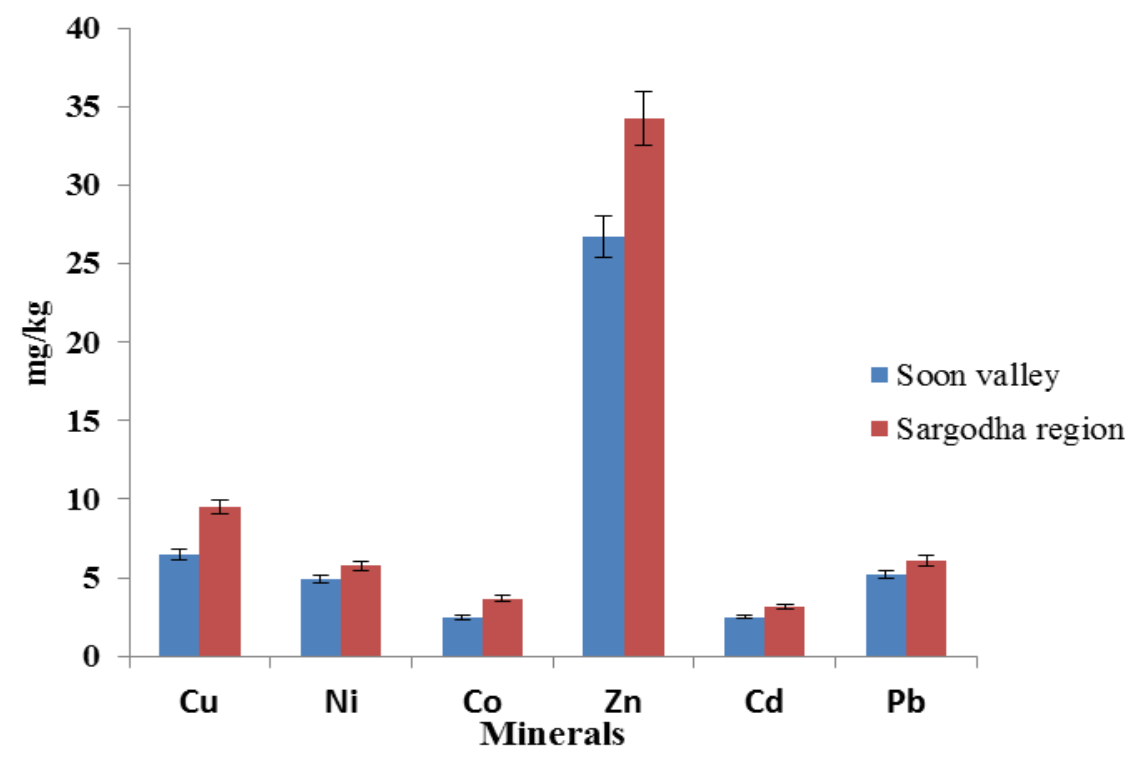

Figure 5. Mineral profile of turnip of two selected regions

\section{Conclusion}

The two selected samples of turnip revealed excellent antioxidant potential. By juxtaposing current study results with earlier employed sources of antioxidants, it is culminated that turnip is a powerful source of antioxidants. Results among two different varieties of turnip showed that antioxidant activity was superior in Sargodha region sample as compared to Soon valley sample. Among two different solvents i.e. methanol and ethanol $(80 \%, 100 \%)$, methanol showed privileged yield as compared to ethanol. Higher antioxidant activity was observed in methanol solvent. Estimation of minerals through wet ash method from the peels of Brassica rapa revealed that $\mathrm{Zn}^{2+}$ concentration in turnip was highest $34.21 \mathrm{mg}$ in Sargodha region as compared $26.73 \mathrm{mg}$ in Soon valley. So, present results concluded that Sargodha region turnip showed maximum antioxidant activity and mineral profile as compared to Soon valley region turnip.

\section{Authors' contributions}

Conceived and designed the experiments: $\mathrm{T}$ Mehmood \& $M$ Iqbal, Performed the experiments: $\mathrm{S}$ Bashir \& $\mathrm{F}$ Siddique,
Analyzed the data: T Mehmood, Z Jabeen \& $\mathrm{H}$ Arshad, Contributed reagents/ materials/ analysis tools: $\mathrm{T}$ Mehmood \& $\mathrm{M}$ Iqbal Wrote the paper: T Mehmood, F Siddique \& $\mathrm{H}$ Arshad.

\section{References}

1. Dimitrios B (2006). Sources of natural phenolic antioxidants. Trends Food Sci Technol 17(9): 505-512.

2. Shahidi F, Janitha PK \& Wanasundara PD (1992). Phenolic antioxidants. Critical reviews in food science and nutrition 32(1): 67-103.

3. Isabelle M, Lee BL, Ong CN, Liu X \& Huang D (2008). Peroxyl radical scavenging capacity, polyphenolics, and lipophilic antioxidant profiles of mulberry fruits cultivated in Southern China. J Agricultural food chem 56(20): 9410-9416.

4. Isabelle $\mathrm{M}$, Lee BL, Ong CN, Liu X \& Huang D (2008). Peroxyl radical scavenging capacity, polyphenolics, and lipophilic antioxidant profiles of mulberry fruits cultivated in Southern China. J Agricultural food chem 56(20): 9410-9416. 
5. Eruvbetine D, Tajudeen ID, Adeosun AT \& Olojede AA (2003). Cassava (Manihotesculenta) leaf and tuber concentrate in diets for broiler chickens. Bio resource Technol 86(3): 277-281.

6. Saeed MK, Anjum S, Ahmad I, Alim-un N, Ali S, Zia A \& Ali S (2012). Nutritional fact and free radical scavenging activity of turnip (Brassica rapa) from Pakistan. World Appl Sci J 19(3): 370-375.

7. Benhammou V, Warszawski J, Bellec S, Doz F, Andre N, Lacour B \& Clavel J (2008). Incidence of cancer in children perinatally exposed to nucleoside reverse transcriptase inhibitors. Aids 22(16): 2165-2177.

8. Fu L, Bo-Tao X, Xiang-Rong X, RenYou G, Zhang Y, En-Qin X \& Hua-Bin L (2011). Antioxidant capacities and total phenolic contents of 62 fruits. Food Chem 129(2): 345-350.

9. Basniwal PK, Suthar M, Rathore GS, Gupta R, Kumar V, Pareek A \& Jain D (2009). In vitro antioxidant activity of hot aqueous extract of helicteresisora Linn. fruits. Niscair $P R$ 8(5): 483-487.

10. Ahmad D, Waheed A, Chaudry MA, Khan SR, Hanan A \& Barkat M (2011). Nutritional and antimicrobial studies on leaves and fruit of Carissa opaca stapf ex haines. Asian J Chem 23(5): 20722076.

11. Shajiselvin CD \& Muthu AK (2011). Antioxidant activity of various extracts from whole plant of Bauhinia Purpurea (Linn): An in-vitro evaluation. $J$ Advanced pharm Res 2(1): 31-37.

12. Twyman RM (2005). Wet Digestion. University of New York, York, Elsevier pp. 4503-4510.

13. Anjorin TS, Ikokoh $\mathrm{P} \&$ Okolo $\mathrm{S}$ (2010). Mineral Composition of Moringa oleifera leaves, pods and seeds from two regions in Abuja, Nigeria. Int J Agric Biol 12(3): 1560-8530.
14. Venkatesh P, Dinakar A \& Senthilkumar N (2011). Hepatoprotective activity of an ethanolic extract of stems of Aniso chilus carnosus against carbon tetrachloride induced hepatotoxicity in rats. Int $J$ Pharma Pharmaceut Sci 3(1): 243- 245.

15. Hsu JL, Su CY \& Lin JW (2006). Resection of a granular cell tumour of the larynx followed by medialization laryngoplasty with bipedicled sternohyoid muscle transposition. Otolaryngol 135(6): 983-985.

16. Chen CC, Liu LK, Hsu JD, Huang HP, Yang MY \& Wang CJ (2005). Mulberry extract inhibits the development of atherosclerosis in cholesterol-fed rabbits. Food Chem 91(4): 601-607.

17. Hussein HK, Elnaggar MH \& AlZahrani NK (2012). Antioxidant role of folic acid against reproductive toxicity of cyhalothrin in male mice. Global Adv Res J Environ Sci Toxicol 1(4): 066071.

18. Mattila P \& Hellstrom J (2007). Phenolic acid in potatoes, vegetables and some of their products. J Food Compos Anal 20(3-4): 152-160.

19. Sultana B, Anwar F \& Ashraf M (2009). Effect of extraction solvent / technique on the antioxidant activity of selected medicinal plants extracts. Molecules 14(6): 2167-2180.

20. Liu S, Manson JE, Lee IM, Cole SR, Hennekens CH, Willett WC \& Buring JE (2000). Fruit and vegetable intake and risk of cardiovascular disease: The Women's Health Study. American $J$ Clin Nutr 72(4): 922-928.

21. Tian Y, Bi J, Shui G, Liu Z, Xiang Y, Liu Y, Wenk MR, Yang H \& Huang X (2011). Tissue-autonomous function of Drosophila seipin in preventing ectopic lipid droplet formation. PloS Genet 7(4): e1001364. 
22. Smith RM (2002). Extractions with superheated water. $J$ Chromatogr 975(1): 31-46.

23. Zuo Y, Wang C \& Zhan J (2002). Separation characterization and quantitation of benzoic and phenolic antioxidants in American cranberry fruit by GC-MS. J Agricultural food chem 50(13): 3789-3794.

24. Soetan KO, Olaiya CO \& Oyewole OE (2010). The importance of mineral elements for humans, domestic animals and plants: A review. African J Food Sci 4(5): 200-222.
25. Molahoseini H, Feizi M \& Seilsepour M (2012). The concentration of some essential elements and cadmium in sunflower, turnip and forage corn under wastewater irrigation. The $1^{\text {th }}$ international and The $4^{\text {th }}$ international Congress on Recycling of Organic Waste in Agriculture, Isfahan, Iran. pp. 26-27.

26. Palowski GA (1987). Quantitative determination of mineral content of geological samples by X-ray diffraction. American Miner 72: 441-443. 